\title{
A TECTÔNICA EXTENSIONAL PALEOPROTEROZÓICA NA BORDA SUDESTE DO CRATON SÃO FRANCISCO (SE, BRASIL): GEOQUÍMICA E PETROLOGIA DAS METAÍGNEAS
}

\author{
Tania Mara Dussin
}

\begin{abstract}
This work presents an assembly of geological, geochemical and petrological data concerning different episodes of magmatism related to Espinhaço Basin evolution in the central part of Minas Gerais State, with a goal to understand aspects of paleoproterozoic crust and tensional tectonic. Metamagmatic rocks are represented by alkaline flows, tholeitic gabbros and basalts and subalkaline granites and rhyolites. Geological and geochemical data indicate magma genesis in an anorogenic context at about $1.7 \mathrm{Ga}$. Taken together, all these magmatic episodes reflect great rigidity of the Paleoproterozoic continental crust and indicate that magma genesis process occurred whenever there was a resurgence of crustal extension, fracturing and rifting, deep melting and the provision of conduits for the mantle heat and mantle magmas to rise into and melt the crust.
\end{abstract}

\section{INTRODUÇÃO}

A região da Cordilheira do Espinhaço, na porção central de Minas Gerais, é uma zona de deformação e metamorfismo policíclicos que bordeja a sudeste o Craton do São Francisco. A geologia da região tem sido alvo de inúmeros estudos, em parte motivados pela ocorrência de ouro e diamante, explorados na região dêsde o século XVI. Entretanto, estudos a respeito da natureza e evolução das rochas metamagmáticas que ocorrem na região da Cordilheira em geral e sôbre o magmatismo relacionado à evolução do rift Espinhaço em particular, são raros e muito mais recentes. $\mathrm{O}$ avanço do conhecimento sôbre a região, com aparecimento de novos dados geológicos e geocronológicos, tem demonstrado que diferentes episódios magmáticos são relacionados a este evento extensional - (a) vulcanismo de filiação alcalina acompanhou a sedimentação inicial na bacia de deposição; (b) magmas máficos de filiação toleítica foram intrudidos nas margens da bacia cortando sequências metassedimentares paleoproterozóicas; magmas graníticos (c) intrudiram o embasamento granito-gnáissico ao longo da zona de rift, nas margens da bacia e em direção a leste, e (d) formaram derrames no interior da bacia originando rochas riolíticas. Resultados sôbre estudos geológicos, em especial geoquímicos e geocronológicos destes diferentes episódios magmáticos são aqui reunidos com o objetivo de contribuir para o entendimento do contexto tectônico no qual evoluiram, da natureza da crosta paleoproterozóica e das interações crosta-manto no período.

\section{CONTEXTO GEOLÓGICO}

A Cordilheira do Espinhaço é uma estrutura de direção submeridiana que se estende da região do Quadrilátero Ferrífero para norte por mais de $1000 \mathrm{~km}$. Insere-se no contexto da faixa de dobramentos Araçuaí, estruturada no Neoproterozóico durante a Orogênese Brasiliano-Panafricana. A Cordilheira é composta principalmente por um espêsso pacote de metassedimentos do tipo rift - o Supergrupo Espinhaço (Pflug \& Renger 1973, Schöll \& Fogaça 1979), que repousa sôbre terrenos granito gnáissicos e sequências supracrustais de idades arqueano-paleoproterozóicas (Figura 1).

A porção basal do Supergrupo Espinhaço (Grupo Diamantina) é constituída por uma sequência de quartzitos, metaconglomerados localmente diamantíferos, fluxo de detritos e metapelitos que constituem, depósitos da fase rift. Esta sequência sedimentar é característica de deposição em ambiente continental com facies de leque aluvial, fandelta, fluvial entrelaçado e lacustre (Garcia \& Uhlein 1987, Martins Neto et al. 1988). A sedimentação foi influenciada pela atividade tectônica e os depósitos desta fase são característicamente marcados por rápidas e frequentes variações faciológicas, consequentes da movimentação de falhas normais norte-sul e falhas transfer leste-oeste (Martins Neto 1993). As condições aluviais na Bacia Espinhaço terminam com uma transgressão marinha registrada pela deposição de metassedimentos quartzosos de grande maturidade e metapelitos de ambiente marinho raso na Formação Sopa-Brumadinho (Martins Neto 1993). Em direção ao topo, estes 
sedimentos gradam a espêssas camadas de quartzitos finos com elevado grau de maturidade e estratificações cruzadas de grande porte (Formação Galho do Miguel) registrando a instalação de um ambiente eólico costeiro (Dossin et al. 1987). A sedimentação continua com a deposição da sequência de topo do Supergrupo
Espinhaço (Grupo Conselheiro Mata). Uma alternância de metassiltitos e filitos com quartzitos finos e bem selecionados característicos de sistemas deposicionais marinho raso sob a influência de ondas e marés (Garcia \& Uhlein 1987), constitui a unidade registrando a atuação de ciclos transgressivos e regressivos na bacia.

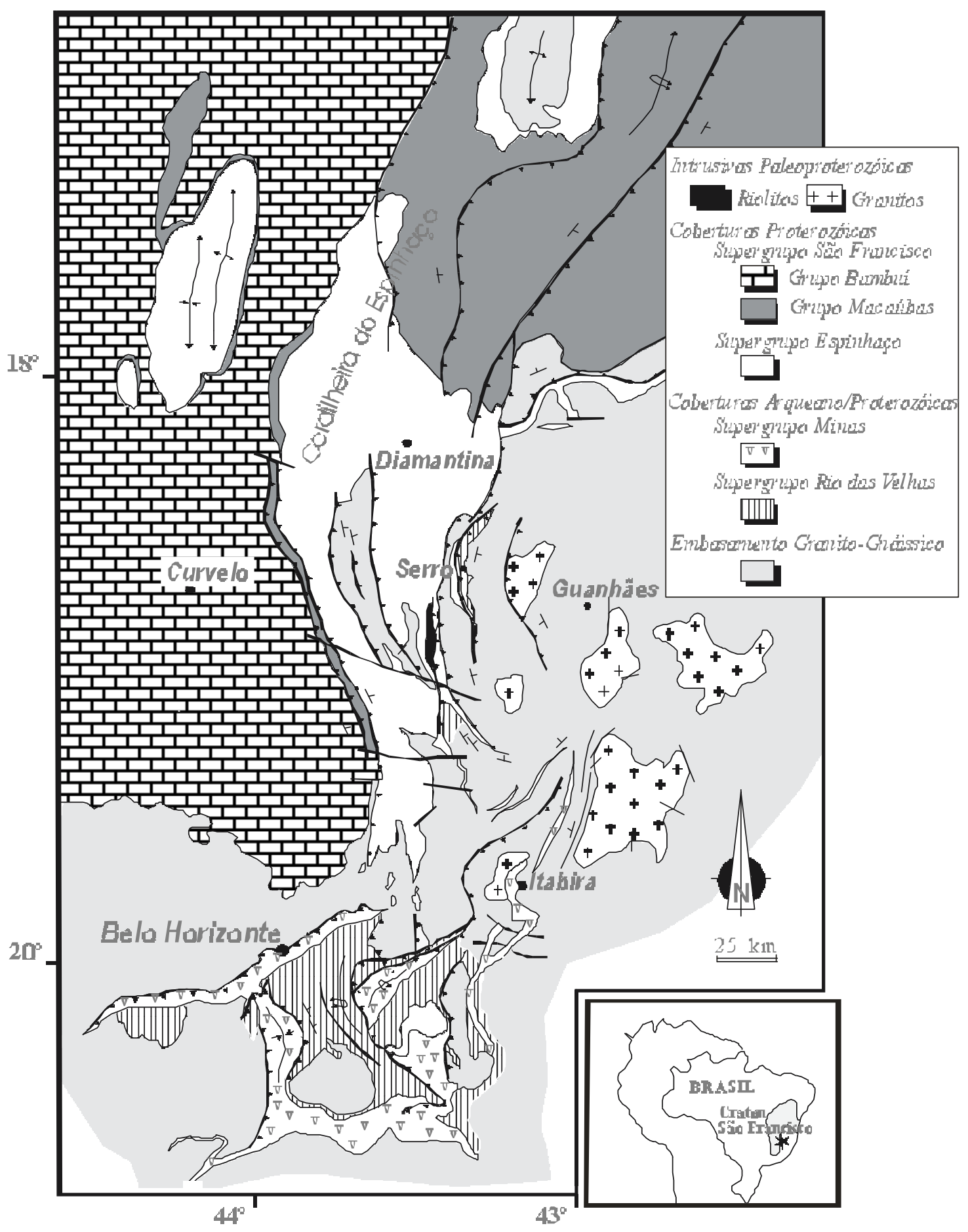

Figura 1. Mapa esquemático das regiões do Espinhaço Meridional e Quadrilátero Ferrífero, borda sudeste do Craton São Francisco. Modificado de Schobbenhaus et al. (1984).

Figure 1. Schematic map of Southern Espinhaço and Quadrilátero Ferrífero, southeastern border of São Francisco Craton. After Schobbenhaus et al. (1984). 


\section{GEOLOGIA, GEOQUÍMICA E PETROLOGIA DAS METAÍGNEAS}

\section{Magmatismo Alcalino}

Rochas metavulcânicas/vulcanoclásticas ocorrem de forma subordinada cortando ou intercaladas com os metassedimentos da fase rift. São mais abundantes na porção central da bacia, próxima à cidade de Diamantina. Ocorrem preenchendo diques verticais de direção NS e EW ou como fluxos com intercalações de tufos.Em alguns locais, as relações estratigráficas entre o vulcanismo e a sedimentação são bastante claros e indicam que o vulcanismo começou num estágio precoce da bacia e esteve ativo durante a sedimentação das formações São João da Chapada e SopaBrumadinho.

A extrusão de magmas deu origem a dois tipos metamórficos distintos: clorita xistos e rochas sericíticas ricas em ferro. O primeiro tipo é mais raro e tem ocorrência relativamente restrita na bacia. São xistos essencialmente contituídos por clorita, sericita, quartzo e óxidos de ferro, com zircão e apatita acessórios. Ocorrem como horizontes de pequena espessura e restrita continuidade lateral, ou diques cortando quartzitos e conglomerados. O segundo tipo é o mais abundante. São rochas acinzentadas, de densidade elevada, coerentemente com sua mineralogia essencial representada por sericita e óxidos de ferro e ferrotitânio. Por sua semelhança com filitos de natureza sedimentar, este tipo litológico tem sido referido na bibliografia como filito hematítico. Estas rochas sofreram importantes processos de alteração metamórfica e apresentam mineralogia e composições químicas não usuais para rochas magmáticas. Em zonas de menor deformação mostram ainda preservadas texturas intersertal e porfirítica com substituição da mineralogia primária por sericita e óxidos de ferrotitânio. Mostram altos conteúdos de $\mathrm{K}_{2} \mathrm{O}(4-9 \%), \mathrm{TiO}_{2}$ (4-7\%), $\mathrm{Al}_{2} \mathrm{O}_{3}(18-24 \%), \mathrm{FeO}$ total $(16-37 \%)$ e de elementos traços litofílicos, como $\mathrm{Zr}$ (400-700ppm), $\mathrm{Y}(20-70 \mathrm{ppm}), \mathrm{Nb}$ (10-60 ppm) e de elementos terras raras totais, os quais apresentam enriquecimentos da ordem de 200 a 500 vezes relativamente aos valores condríticos e curvas de distribuição que indicam fracionamento preferencial dos elementos leves, com razões $(\mathrm{La} / \mathrm{Yb})_{\mathrm{N}}$ podendo atingir até 17,6 em algumas amostras (Dussin 1994). Os dados geoquímicos sôbre as concentrações destes elementos traços indicam que estes tiveram uma mobilidade restrita durante os processos de alteração mostrando curvas de distribuição similares e valores absolutos em amostras coletadas em diferentes situações relativamente aos ambientes de deposição na bacia de sedimentação, geografia e posicionamento estratigráfico (Figura 2).

Estudos geocronológicos indicam idades de cristalização para estas metavulcânicas de 1710ะ12 Ma $\left({ }^{207} \mathrm{~Pb} /{ }^{206} \mathrm{~Pb}\right.$ sôbre zircões, Dussin et al. 1995).

A determinação do protólito magmático destas rochas é uma questão complexa em função da extensa alteração secundária a que elas foram submetidas e a literatura tem registrado uma longa controvérsia sôbre o assunto (Moraes \& Guimarães 1930, Correns 1932, Barbosa 1951, Knauer \& Schrank 1993). Entretanto, os dados geoquímicos atualmente disponíveis para as metavulcânicas indicam derivação a partir de magmas de trend alcalino gerados a partir de baixas taxas de fusão de fontes mantélicas, possivelmente de composição condrítica (Herrgesell 1984, Dussin 1994).
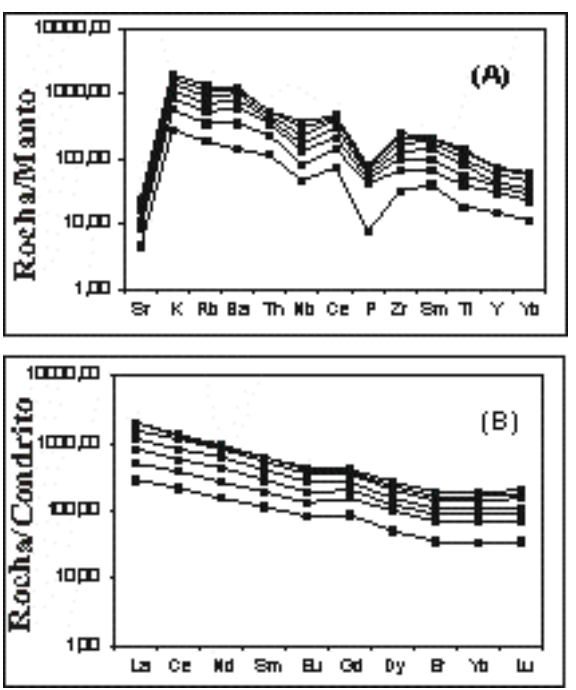

Figura 2: Composição química de amostras representativas de filitos hematíticos: (A) elementos traços litofílicos normalizados à composição do manto primordial (Sun \& McDonough, 1989) e (B) elementos terras raras normalizados aos condritos (Evensen et al., 1978).

Figure 2. Chemical composition from representative samples of hematitic phyllite: (A) lithophilic trace elements normalized toprimordial mantle (Sun \& McDonough, 1989) and (B) rare earth elements normalized to condrite (Evensen et al., 1978).

\section{Magmatismo Básico}

Rochas gabróicas são encontradas na porção sul da Cordilheira intrudindo sequências metassedimentares paleoproterozóicas e estruturas deformacionais da região do Quadrilátero Ferrífero. O corpo melhor conhecido ocorre nas proximidades de Ibirité. Silva et al. (1995) descrevem um metagabro de textura intergranular, com labradorita e augita como principais minerais componentes, e ilmenita como acessório. Os dados geocronológicos registram idades de cristalização de $1714 \pm 5 \mathrm{Ma}$ (U/Pb em zircões).

Metabásicas de natureza vulcânica ocorrem intercaladas em metassedimentos numa estreita bacia de direção submeridiana, que aflora, ao longo de falhas NNE-SSW, no Vale do Rio Guanhães, a norte da Cidade de Guanhães e a leste da principal bacia de sedimentação. A sequência sedimentar compreende anfibolitos, mica xistos, quartzitos e metapelitos. Os 
dados geocronológicos indicam idades de cristalização de $1697 \pm 10 \mathrm{Ma}$ (Dussin et al. 2000). Esta ocorrência registra uma extensão dos processos de fraturação crustal e sedimentação paleoproterozóicos em direção a leste, muito além do que previamente reconhecido.

O conhecimento sôbre estas ocorrências são escassos. Resultados geoquímicos disponíveis indicam cristalização a partir de magmas de natureza subalcalina e filiação toleítica, enriquecidos em ferro e com elevadas concentrações de elementos traços litofílicos, especialmente $\mathrm{Th}, \mathrm{Zr}, \mathrm{Zr} / \mathrm{Y}$, e elementos terras raras com fracionamento preferencial de elementos leves. Estas características são compatíveis com aquelas de basaltos intraplaca.

\section{Magmatismo Ácido}

Magmas graníticos intrudiram o embasamento granito-gnáissico nas bordas da bacia ou extrudiram no seu interior gerando rochas de composições riolíticas. Para o conjunto destas rochas plutônicas e vulcânicas tem sido usada a designação de Suíte Borrachudos (Dussin 1994), numa extensão do termo originalmente utilizado para o pluton aflorante nas proximidades da Cidade de Itabira. Em sua ascenção, os magmas Borrachudos utilizaram lineamentos e falhas de direcionamento geral NS, paralelas ao eixo principal do rift, sendo comum um alongamento dos plutons segundo esta direção.

Granitos e riolitos mostram composições mineralógicas e químicas semelhantes, com feldspato alcalino, quartzo, biotita e hastingsita como minerais essenciais e altas concentrações de $\mathrm{SiO}_{2}, \mathrm{~K}, \mathrm{Fe}, \mathrm{F}, \mathrm{Nb}$, $\mathrm{Y}, \mathrm{Zr}$, Ga e elementos terras raras (Figura 3). Todas as características geológicas, mineralógicas e geoquímicas são compatíveis com as de granitos tipo A intrudidos em contexto anorogênico. Dados geocronológicos indicam idades em torno de 1730-1770 Ma (Dossin et al. 1993; Fernades et al. 2000) para granitos e 1710 $1770 \mathrm{Ma}$ (Brito Neves et al. 1979; Machado et al. 1989) para riolitos. Todas as amostras analisadas são ricas em LREE, $\operatorname{com}^{147} \mathrm{Sm} /{ }^{144} \mathrm{Nd}$ variando de 0,11 a 0,13 . Valores iniciais de $\mathrm{e}_{\mathrm{Nd}}$ para granitos e riolitos, calculados para $1730 \mathrm{Ma}$, estão entre $-10,1$ e $-6,17$ e a razão inicial ${ }^{87} \mathrm{Sr} /{ }^{86} \mathrm{Sr}$ é de 0,7057 (Dussin 1994, Dussin et al. 1997). Idades modelo $\mathrm{T}_{\mathrm{DM}}$ variam de 3,0 a 2,6 Ga.

Os dados geoquímicos disponíveis são indicadores de alguns aspectos da gênese dos magmas Borrachudos. As altas razões $\mathrm{Na}+\mathrm{K} / \mathrm{Ca}$, Fe/Mg e Ga/Al podem ser resultantes da fusão de micas residuais na fonte e da natureza altamente refratária de plagioclásios cálcicos e fases máficas residuais. Altas concentrações de F corroboram estas hipóteses. A estabilidade de micas e anfibólios em sólidos residuais, segundo dados termodinâmicos, é dependente de altas concentrações deste elemento. Além disto, as altas concentrações de cations como $\mathrm{Zr}$, Nb e elementos terras raras esta diretamente relacionada ao conteúdo de halógenos no magma, particularmente $\mathrm{F}$, o qual distorce a estrutura dos aluminosilicatos, fornecendo sítios para estes cátions e estabilizando complexos metálicos (Collins et al. 1982). A sistemática dos isótopos Sm-Nd e RbSr indicam gênese de magmas por fusão de fontes da crosta inferior. Dussinet al. (1997), mostraram, através da variação de $\mathrm{e}_{\mathrm{Nd}}$ com o tempo, uma estreita correlação entre a evolução dos magmas Borrachudos e a da crosta transamazônica, sugerindo que esta pode ser considerada a principal fonte magmática.
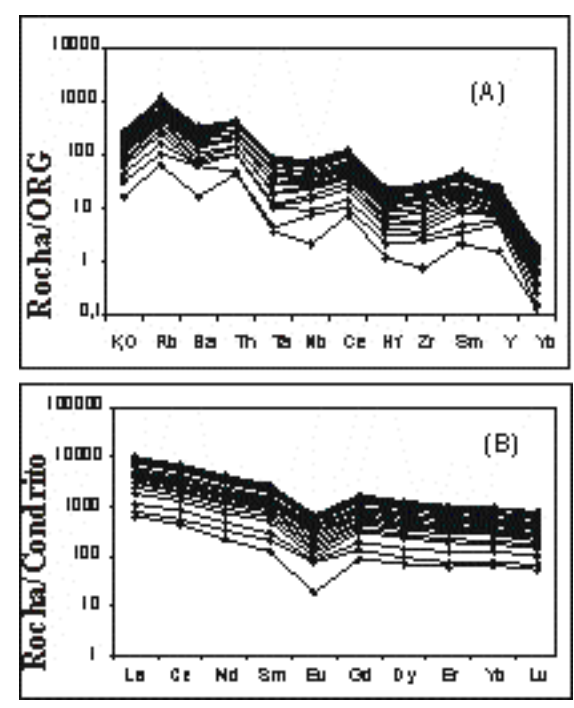

Figura 3. Composição química de amostras representativas de granitos da Suíte Borrachudos: (A) elementos traços litofílicos normalizados à composição do ORG de Pearce et al. (1984); e (B) elementos terras raras normalizados aos condritos de Evensen et al. (1978).

Figure 3. Chemical composition from representative samples of Borrachudos granites: (A) lithophilic trace elements normalized to ORG (Pearce et al., 1984) and (B) rare earth elements normalized to condrites (Evensen et al., 1978).

Granitos e riolitos com estas características têm sido descritos exclusivamente na região da borda leste da Cordilheira do Espinhaço, constituindo a Suíte Borrachudos. Entretanto, numerosas outras ocorrências de rochas vulcânicas de natureza riolítica intercaladas com metassedimentos Espinhaço, e de plutons graníticos intrudindo o embasamento da bacia em suas porções mais internas ou em suas margens têm sido descritos em direção ao norte, nos estados de Minas Gerais e Bahia. O conhecimento disponível sôbre estas ocorrências é relativamente restrito, mas as semelhanças em termos de suas características mineralógicas e geoquímicas, são sugestivas de estreita correlação com a Suíte Borrachudos. 


\section{IMPLICAÇÕES SÔBRE A EVOLUÇÃO DA TECTONNICA E CROSTA PALEOPROTEROZÓICAS}

A transgressão marinha no tôpo da Formação SopaBrumadinho, marca uma mudança no regime de subsidência da bacia que passa de predominantemente mecânico a uma subsidência térmica e flexural (Chang et al. 1988, Uhlein 1991). Esta mudança de regime traduz condições de quiescência tectônica em relação à ambiência de deposição da fase rift. A deposição de sedimentos terrígenos, característicamente pouco extensos e irregulares da fase rift, foi acompanhada por extrusões de magmas no interior da bacia e por intrusões no seu embasamento. Os dados geocronológicos disponíveis para este conjunto de rochas magmáticas que acompanhou a fase rift, indicam atividade tectônica se estendendo por um longo período, equivalente a cerca de $70 \mathrm{Ma}$. A fase pós-rift dá lugar a depósitos extensos e regulares. Não são conhecidos registros de atividade ígnea no período.

As características da sedimentação (continental e marinho-raso) indicam que a Bacia Espinhaço foi um rift assimétrico, de natureza ensiálica (Costa \& Inda 1982, Uhlein 1991). A concentração do magmatismo granítico a leste da bacia, a natureza do magmatismo que acompanhou as fases iniciais de evolução do rift, bem como suas características geoquímicas, corroboram estas interpretações.

Os processos que levaram à gênese de magmas de naturezas diversas estiveram diretamente relacionados à mudança do equilíbrio dinâmico na interface crostamanto durante os esforços tectônicos que levaram à extensão e fraturamento da crosta. $\mathrm{O}$ adelgaçamento litosférico foi compensado pelo uplift da astenosfera. Fusão por descompressão de fontes mantélicas (composição condrítica?) levou à formação de magmas alcalinos que alimentaram o rift. Magmas toleíticos de caráter básico, intrudidos nas bordas da bacia ou como derrames no interior da bacia, são possivelmente formados por mecanismo semelhante em condições de menor pressão. Em sua ascenção para a superfície, se diferenciaram e assimilaram material crustal. Estas rochas precisam, entretanto, ser melhor estudadas antes que estas idéias possam ser detalhadas. A subida de magmas mantélicos, ou o calor despreendido do manto, forneceu a energia necessária para produzir fusão de fontes empobrecidas da crosta inferior gerando os magmas Borrachudos.

O conhecimento disponível sôbre a extensão Espinhaço favorece a idéia de um evento distinto mais do que uma manifestação continuada do colapso que se seguiu à Orogênese Transamazônica (2,1 a 1,9 Ga; Teixeira et al. 1989, Barbosa 1993). Os dados indicam que os processos de gênese de magmas ocorreram em resposta à extensão de uma crosta rígida, com fraturamento e rifting, fusão profunda e a formação de condutos para o calor do manto e magma mantélico ascenderem e produzirem fusão da crosta. Magmas formados alimentaram o rift intercalando-se com metassedimentos, ou se intrudiram nas margens da bacia.

Algumas considerações já foram feitas no passado sôbre a intrusão de magmas de afinidade kimberlítica durante o processo de rifting que levou à formação da Bacia Espinhaço. Não existem, entretanto, evidências que corroborem esta idéia. Resultados de estudos isotópicos de zircões detríticos do conglomerado Sopa (U-Pb por SHRIMP, Chaves et al., 2000) indicaram três populações de cristais, com idades em torno de 3,6, 2,8 e 2,0 Ga, as quais foram interpretadas como eventos magmáticos ocorridos anteriormente, e portanto, sem relação com a fase rifting. A formação de magmas kimberlíticos em qualquer um destes episódios magmáticos ainda é, também, uma questão indeterminada.

\section{AGRADECIMENTOS}

Às agências financiadoras CNPq, CAPES e FAPEMIG, e ao CPMTC/Instituto de Geociências da Universidade Federal de Minas Gerais.

\section{REFERÊNCIAS}

Barbosa O. 1951. Contribuição à origem do diamante em Diamantina, MG, Rio de Janeiro, Bol.DNPM/DGM, 136:1-36. Barbosa J.S.F. 1993. O embasamento do Craton do São Francisco na Bahia: Síntese do Conhecimento Atual. In: SBG, Simp. Craton São Francisco, 2, Salvador. Anais, 1:9-11.

Brito Neves B.B.; Kawashita K. \& Delhal J. 1979. A evolução geocronológica da Cordilheira do Espinhaço: dados novos e integração. Rev. Bras. Geociências, 9(1):71-85.

Chang H.K., Miranda F.P., Magalhães L. \& Alkmim F.F. 1988. Consideração sobre a evolução tectônica da Bacia do São Francisco. In: SBG, Congr. Bras. Geol., 35, Belém. Anais, 5:2076-2090.

Chaves M.L.S.C., Dussin T.M., Sano Y. 2000. The source of the Espinhaço diamonds: evidences from Shrimp U/Pb zircon ages of the Sopa conglomerate and $\mathrm{Pb}-\mathrm{Pb}$ zircon evaporation ages of metavolcanic rocks. Rev. Bras. Geociências, 30(2):265-269.

Collins, W.J., Beams, S.D., White, A.J.R., Chappell, B.W. 1982. Origin of A-type granites with particular references to southeastern Australia. Contrib. Mineral. Petrol., 80:189-200.

Correns C.W. 1932. Über die Diamantenlagerstätten des Hochlandes von Diamantina, Minas Gerais, Brasilien. Zeitsch Prakt. Geol., 10: $161-168,177-181$.

Costa L.A.M. \& Inda H.A.V. 1982. O Aulacógeno do Espinhaço. Ciências da Terra, 2: 13-18.

Dossin I.A., Garcia A.J.V., Uhlein A., Dardenne M.A. \& Dossin T.M. 1987. Facies Eólico na Formação Galho do Miguel, Supergrupo Espinhaço (MG). In: SBG, Simp. sobre Sistemas Deposicionais no Precambriano, Ouro Preto. Anais, 6: 85-96.

Dossin I. A., Dossin T. M., Charvet, J., Cocherie A. \& Rossi P., 1993. Single-zircon dating by step-wise Pb-evaporation of Middle Proterozoic magmatism in the Espinhaço Range, southeastern São Francisco Craton (Minas Gerais, Brazil). In: SBG, Simp. Craton São Francisco, Salvador, Anais, 1:39-42.

Dussin T. M., 1994. Associations plutono-volcaniques de l'Espinhaço méridional (SE-Brésil): un exemple d'évolution de la croûte protérozö̈que. Lab. Geologie Structurale, Univ. Orléans, Orléans, Tese de Doutoramento, 177 p.

Dussin T.M., Dussin I.A., Rossi P. \& Charvet J. 1995. Idade do Supergrupo Espinhaço: determinação ${ }^{207} \mathrm{~Pb} /{ }^{206} \mathrm{~Pb}$ pelo método de evaporação do $\mathrm{Pb}$ sôbre monozircões de metavulcanitos sinsedimentares. In: Simp. Geol. de Minas Gerais, 8, Belo Horizonte, Anais, 1:11-13. 
Dussin T.M., Dussin I.A., Noce C.M. 1997. Tectonic settig and origin of the Mesoproterozoic Borrachudos granites (MG, Brazil). In: South-American Symp. on Isotope Geology, 1, São Paulo, Anais, 1:104-106.

Dussin T.M., Dussin I.A., Macambira M.J.B. 2000. Chronology of Mesoproterozoic Guanhães River Sequence: ${ }^{207} \mathrm{~Pb} /{ }^{206} \mathrm{~Pb}$ Single Zircon Evaporation Data of Metavolcanic Rocks (Minas Gerais, Brazil). In: Inter. Geol. Congress, Rio de Janeiro, Abstracts Vol., CD.

Evensen, N.M., Hamilton, P.J., O’Nions, R.K. 1978. Rare-earth abundances in chondritic meteorites. Geochim. Cosmochin. Acta, 42:1099-1112.

Fernandes M.I.S., Pedrosa Soares A.C., Noce C.M., Wiedeman C. \& Correia Neves J.M. 2000. U-Pb Geochronology of the Borrachudos Suite: Evidence of Brasiliano Tectonism Recorded by Late Paleoproterozoic Anorogenic Granites (Araçuaí Belt, Minas Gerais, Brazil). In: Inter. Geological Congress, Rio de Janeiro, Abstracts Volume, CD.

Garcia A.J.V. \& Uhlein A. 1987. Sistemas deposicionais do Supergrupo Espinhaço na região de Diamantina (MG). In: SBG, Simp. sobre Sistemas Deposicionais no Precambriano, Ouro Preto. Anais, 6: 113-136.

Herrgesell G. 1984. Das Präkambrium am Ostrand der Nördlichen Serra do Cipó (Serra do Espinhaço, Minas Gerais, Brasilien). Geol. Inst. Univ. Albert-Ludwigs, Freiburg. Tese de Doutorado, $247 \mathrm{p}$.

Knauer L.G. \& Schrank A. 1993. A origem dos filitos hematíticos da Serra do Espinhaço Meridional, Minas Gerais. In: CPMTC, Geonomos, 1(1):33-38.

Machado N., Schrank A., Abreu F. R., Knauer L. G. \& Almeida Abreu P. A., 1989. Resultados preliminares da geocronologia U/Pb na Serra do Espinhaço Meridional. In: SBG, Simp. Geol. Núcleo M.G., 5, e Simp. Geol. Núcleo Brasília, 1, Belo Horizonte, Anais, 1:171-174.

Martins Neto M.A. 1993. The sedimentary evolution of a Proterozoic rift basin: the basal Espinhaço Supergroup, southern Serra do Espinhaço, Minas Gerais, Brazil. Geol. Inst. Freiburger Geowiss Beiter, Freiburg. Tese de Doutorado, 155p.
Martins Neto M.A., Almeida Abreu P.A. \& Brichta A. 1988. Sistemas deposicionais das formações São João da Chapada e SopaBrumadinho na região de Diamantina/Costa Sena, MG. In: SBG, Cong. Bras. Geol., 35, Belém. Anais, 5(2):633-647.

Moraes L.J. \& Guimarães D. 1930. Geologia da região diamantífera do Norte de Minas Geraes. Anais da Academia Brasileira de Ciências, 2:153-186.

Schobbenhaus C., Campos D.A., Derze G.R., Asmus H.E. 1984. Mapa Geológico do Brasil e da Área Oceânica Adjacente. Ministério das Minas e Energia/DNPM, Brasília, Brazil.

Schöll W.U. \& Fogaça A.C.C. 1979. Estratigrafia da Serra do Espinhaço na região de Diamantina. In: SBG, Simp. de Geol. de Minas Gerais, 1, Diamantina. Anais, 1:55-73.

Silva A.M., Chemale Jr. F., Heaman L. 1995. The Ibirité Gabbro and the Borrachudos granite - The rift related magmatism of mesoproterozoic age in the Quadrilátero Ferrífero (MG). In: SBG, Simp. Geol. de Minas Gerais, 8, Belo Horizonte, Anais, 1:89-90.

Sun S.S. \& Mcdonough W.F. 1989. Chemical and isotopic systematics of oceanic basalts: implications for mantle composition and processes. In: Saunders A.D. \& Norry M.J.(eds.), Magmatism in Ocean Basins. Geol. Soc. London. Spec. Pub., 42:313-345.

Pearce J.A., Harris N.B.W., Andrew G.T. 1984. Trace element discrimination diagrams for the tectonic interpretation of granitic rocks. J. Petrol., 25:956-983.

Pflug R. \& Renger F. 1973. Estratigrafia e evolução geológica da margem sudeste do Craton Sanfranciscano. In: SBG, Cong. Bras. Geol., 27, Aracajú. Anais, 2:5-19.

Teixeira W., Tassinari C.C.G., Cordani U.G., Kawashita K. 1989. A review of the geochronology of the Amazonian craton tectonic implications. Precambrian Res., 42:213-227.

Uhlein A. 1991. Transição Cráton - Faixa dobrada: um exemplo do Cráton São Francisco e da Faixa Araçuaí (ciclo Brasiliano) no Estado de Minas Gerais. Instituto de Geociências da Universidade de São Paulo, São Paulo. Tese de Doutoramento, 295 p. 